\title{
PREGUNTAS A ANTONIO FERNÁNDEZ ALBA
}

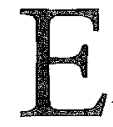

L ESTUDIO DE ANTONIO FERNÁNDEZ ALBA ocupa el ático dúplex de una casa de la que es autor. Un espacio largo y blanco, dibujado por una delicada estructura de vigas vistas e iluminado desde ambos lados por múltiples y pequeñas ventanas. De las paredes cuelgan numerosas maquetas y sobre las mesas se extienden planos de edificios y ciudades.

En esta casa del ensanche madrileño, de ladrillo y racionales fenêtres en longueur, compositivamente funcional y serena, vivieron -y viven- numerosos artistas. La mayoría de ellos, como Saura y Millares - que también tuvieron estudio-, eran del grupo El Paso, del que Fernández Alba formó parte. Otros, como Lucio Muñoz -que compartía con el grupo de los López objetivos artísticos que en aquel momento parecían muy distintos-, vivían en la casa de enfrente. Por hablar en términos groseros, abstractos y realistas bajo un mismo techo.

La relación, las colaboraciones, las polémicas y las mutuas influencias entre artistas de distintas disciplinas han sido siempre un campo fecundo para el progreso de las artes y el análisis de los críticos. Esta relación, que no en todas las épocas se produce con la misma intensidad, fue muy activa y determinante en el Madrid de los primeros años cincuenta.

Los artistas antes citados sintieron desde el principio la necesidad de abrir el panorama cultural y relacionarse con quienes hacían un trabajo de interés en cualquier otro lugar. Por ello se aproximaron a aquellos artistas provenientes de otras ciudades, como Tàpies - reconocido muy tempranamente por la crítica y los clientes de Madrid - y Oteiza - que trabajó muchos años 
en esta ciudad-, o con artistas de otras disciplinas, como Luis de Pablo y su grupo Nueva Música, todos interesados en problemas compositivos semejantes. Y la conversación fue fecunda. Una de las causas que explica esta relación como una necesidad fue la ausencia de maestros de la propia disciplina, como explicó muy bien Luis de Pablo para el caso de la música: entre la música romántica y nacionalista y él no había nadie, por lo que tuvo que acudir a un poeta como Aleixandre para encontrar a un maestro.

Poco más tarde, sin embargo, todo esto cambió, pues cuando todos estos artistas reconocidos por grupos muy minoritarios en su país consiguieron salir y exponer en el exterior, no solo recibieron el premio de la crítica, sino que se encontraron parejos a los artistas de fuera.

Desde el Gran Premio de la Bienal de São Paulo que ganara en 1953 Tàpies, siguieron triunfando Oteiza, también en São Paulo en 1957, junto al grupo El Paso, y este grupo en la Bienal de Venecia de i959. Ese mismo año, en París, Feito ganó el premio, en 1960 Saura ganó el premio Guggenheim, y así sucesivamente.

Hoy, transcurridos cuarenta años, viviendo una situación cultural distinta pero sin duda deudora de aquel momento, tal vez sea útil recordarlo, y para ello nos acercamos, cuestionario en mano, al estudio de Antonio Fernández Alba, quien no solo entonces participó en la aventura que nos interesa, sino que ha seguido construyendo y - lo que para nosotros es más importante- escribiendo sobre arquitectura.

Gabriel Ruiz Cabrero. Antonio, tú que has tenido siempre una intensa relación con los artistas plásticos, los músicos y los escritores, ¿cómo compararías la situación actual con la vivida en los años cincuenta?

Antonio Fernández Alba. Los períodos de intensa actividad creadora son más propicios al intercambio de ideas y experiencias. El arquitecto siempre ha seguido con interés los hallazgos del pensamiento plástico englobado en ese personaje que se denomina artista, de manera que no creo que en la actualidad este vínculo de relación con el trabajo de la plástica haya decaído. Como tantas cosas, en una fase de transición cultural se ha modificado.

G. R. C. En aquel Madrid de los cincuenta, ¿qué te impulsó a buscar la compañía de los artistas? ¿Qué objetivos o 
planteamientos encontraste entre aquellos que no fueran compartidos por los arquitectos o los ingenieros?

A. F. A. Sin duda era una época difícil, donde cualquier transgresión de lo establecido, como norma dictada, resultaba difícil de superar aunque las circunstancias personales te reclamaran otros horizontes. ¿El acercamiento del arte a la vida? El arte siempre ha sido un territorio que ha posibilitado el desarrollo de los valores del hombre en relación con su tiempo. El artista, en general, expresa a su manera estos sentimientos. Por lo tanto, la pintura, la música, la escultura y la literatura fueron, en aquellos tiempos, espacios donde uno podía aprender los rasgos utópicos, comenzar a distinguir los signos emancipadores, conocer los requerimientos sociales, en definitiva aprender a construir el proyecto integral de lo que entonces intuíamos que era la nueva cultura. Personalmente creo que debo el enriquecimiento de haber podido sortear las pequeñas torres de marfil de las disciplinas tecnocráticas, incipientes si se quiere, en las que se desarrollaba la vida profesional de los arquitectos de entonces al panorama del entorno artístico y profesional donde yo me movía.

G. R. C. El otro día Luis de Pablo me contaba, hablando de estas cuestiones, que tu interés por la música en aquellos días se centraba sobre todo en la teoría de las investigaciones compositivas que ellos, los músicos, desarrollaban. ¿Qué aprendiste de aquella aproximación a músicos y artistas plásticos?

A. F. A. El comercio formal en el que se desarrollan muchos de los trabajos del arquitecto puede, en ocasiones, optar por una traslación hacia la arquitectura de los hallazgos obtenidos en el mundo del arte de una manera mimética, pero los métodos y formas de expresión son específicos de cada una de las disciplinas artísticas.

G. R. C. Estas diferencias entre las distintas disciplinas artísticas que mencionas se ponen muy de manifiesto en las respectivas relaciones que cada una mantiene con la sociedad en sus distintas manifestaciones, sea como público o como cliente. Sería interesante saber cuáles eran los objetivos comunes en este sentido, de qué manera confiabais intervenir en la vida social, y más concretamente - en tu condición de arquitecto-, de qué manera pensabais que vuestro trabajo podía transformar la ciudad y cuáles eran las relaciones entre producción arquitectónica y política. 
A. F. A. Por aquellos años era elocuente el interrogante de cómo descubrir y consolidar la «modernidad» en el espacio social de la época. La «racionalidad» que esgrimían las doctrinas del Movimiento Moderno servía de apoyo para trabajar en aquellos proyectos aún artesanales bajo el epígrafe, un tanto ingenuo desde la perspectiva de hoy, de "Geometrías de la razón». Estos proyectos anhelaban concebir los lugares de la ciudad moderna como unos espacios autónomos con respecto a la naturaleza. Una aventura un tanto ilusoria, de manera que más tarde se convertirían en ejercicios de composición, más o menos arquitectónicos, encuadrados en los dominios de la racionalidad técrica.

En cuanto a las influencias recíprocas entre arte y política, la historia de la arquitectura las recoge en todas las épocas con bastante precisión, y este período no ha sido una excepción.

G. R. C. Repasando aquellos días políticamente difíciles, en los que la información artística y arquitectónica era escasa, estaría bien recordar lo que en aquellos años de aprendizaje veías de útil a tu alrededor, y cuáles eran tus deseos y objetivos.

A. F. A. En un período de aprendizaje, todo aquello que se construye con cierta lógica edificatoria tiene unos valores que pueden incrementar nuestros conocimientos. En aquellos años, en Madrid y en general en España, existían aún equipos de magníficos artesanos herederos de los gremios del buen arte de construir. De manera que las corrientes eclécticas que invadían las composiciones arquitectónicas, por muy dudosas e incluso anacrónicas que fueran, siempre venían apoyadas por construcciones decentes y en ocasiones significativas. La reconstrucción de la Ciudad Universitaria, los edificios del Consejo Superior de Investigaciones Científicas, el Ministerio del Aire, los trabajos de la Dirección de Regiones Devastadas, todos ellos eran edificios y conjuntos que se trasformaban en auténtico aprendizaje.

En lo concerniente a tu segunda pregunta, debo señalar que no tengo muy claros los deseos, aunque de manera menos confusa podrían perfilarse los fines. Me atraía la moral que alimentaba el cambio revolucionario de las vanguardias, la belleza de la visión abstracta de aquellos espacios que escasamente difundían las publicaciones de entonces, los enunciados democráticos que llevaba implícito el proyecto de la arquitectura de la ciudad. 
$\mathrm{Y}$, sin duda, la arquitectura era para mí en aquellos tiempos un medio de liberación y conocimiento, en fin, una categoría esencial en el curso adolescente de la vida.

G. R. C. En un libro titulado La crisis de la arquitectura española, 1939-1972, escribiste: «La falta de maestros, la situación de indigencia cultural a que están sometidas las generaciones nacidas a la vida española con posterioridad a la Guerra Civil del 36, impedían cualquier opción formalizadora. Tendían a confundir aún más, si esto fuera posible, las orientaciones pedagógicas que en las escuelas de Arquitectura se intentaba suscitar. En el fondo, la situación era realmente más triste y equívoca. Estos centros, de hecho, no existían ni existen en la actualidad como centros de conocimiento e investigación, sino como simples lugares de trámites burocrático-administrativos donde el alumno retira sus expedientes académicos. Esta brutal soledad a que es sometido el alumno, que requiere durante el período pedagógico una orientación y un estímulo, provocaría más tarde fricciones muy específicas con los cambios de planes de estudio y con el despertar de una conciencia «dialéctica» de las generaciones que no conocieron las motivaciones de la Guerra Civil, y que desembocarían en un «autodidactismo» $\sin$ límites, fruto del cual ha nacido la escasa y compleja aportación de la actual arquitectura en España. A esta orientación «autodidácticas de las décadas de los cuarenta y los cincuenta se debe la mayor parte de la aportación arquitectónica en nuestro país, y en ella se puede observar una serie de constantes que facilitan un esquema orientativo de tendencias significativas dentro del panorama arquitectónico nacional.

La falta de escuelas de Arquitectura con una estructura rigurosa que pudieran haber ofrecido a las generaciones posteriores una actitud más analítica y objetivadora de cuestiones impidió acabar con este «autodidactismo» de formación liberal, como había sucedido en la novela española de la Generación de los 50.

Personalmente, ¿te consideras un autodidacta?

A. F. A. Resulta difícil delimitar o excluir los agentes del magisterio. Te diré que no era época de maestros, aunque sin duda existían. De cualquier forma, no creo que mi referencia personal sobre este aspecto tenga interés alguno. Mi aprendizaje fue difuso, más inclinado al acontecer de los fenómenos artísticos, 
salpicado por los desafíos y las rupturas de esos acontecimientos. $Y$ al mismo tiempo, por un afán de conocer el oficio del «constructor del lugar», que yo creo que es donde reside la verdadera práctica de la arquitectura, y lograr una información de lo que acontecía fundamentalmente en Europa. Pienso que en esta actividad profesional uno es autodidacta por naturaleza, con el apoyo de la experiencia de la historia, tal vez la disciplina más difícil de leer $y$, sobre todo, de interpretar.

G. R. C. Hablas de lo que acontecía en Europa y, precisando tú pensamiento sobre la situación anterior a 1960 -cuando irrumpes en la escena crítica madrileña-, escribiste: «Superados los primeros impulsos del impacto que significó la obra de los "grandes maestros", el racionalismo daría paso a un lenguaje ambiguo de la "función", cuya única misión posible era justificar la razón arquitectónica. En estas propuestas la ordenación en planta obedece a unos esquemas geométricos muy simples, donde la función de los distintos espacios está sometida a la escala rítmica de la composición que reclamen los alzados y la estructura como elemento determinante de este ritmo. Arquitectura cuyos valores residen principalmente en un impacto visual, arquitectura nacida más del impulso puramente "expresionista" que de un planteamiento racional de los problemas arquitectónicos [...]».

Cuéntanos cuáles fueron para ti las figuras más influyentes de la arquitectura por aquellos años.

A. F. A. Por citar nombres-que siempre implican o pretenden ser solidarios de conceptos-, señalaría como figuras significativas en mi formación a arquitectos como A. Gaudí, F. Ll. Wright, G. Asplund, L. Kahn y A. Aalto. Las deudas, en mi caso personal, serían muy largas de citar, como no puede ser menos en una época que se había iniciado con los fulgores de la «modernidad" y el "progreso», y que construía ante nuestra mirada los retablos barrocos de la nueva emblemática tecnológica, junto a la invasión de la construcción mercantilizada. En fin, la fractura entre «idea» y «forma», este conglomerado de acontecimientos vividos en un país que no era protagonista sino antagonista de la dinámica de su tiempo, hacía que toda luz que iluminase cualquier apertura se aceptara como una atractiva influencia.

G. R. C. Conocidas las influencias sobre tu obra, me gustaría que nos contaras ahora qué te indujo, como profesor, a 
explicar la arquitectura de dos maestros como Wright y Aalto, lo que entonces te hizo ser considerado el introductor de su trabajo en la Escuela de Madrid.

A. F. A. F. Ll. Wright me parece que ha realizado la síntesis espacial más hermosa de la arquitectura del siglo XX. En Wright se encuentran muchas de las sinfonías espaciales que se han compuesto durante el siglo que termina, y que permanecen abiertas a las nuevas visiones que suscita la arquitectura de los ingenieros, los nuevos morfólogos del espacio técnico.

En un libro de próxima publicación recojo las notas que por aquellos años escribí para preparar los viajes que, como profesor, realizaba con los alumnos de la Escuela de Madrid. La arquitectura de los países nórdicos encajaba en esas lecciones casi elementales con las que tienes que explicar y explicarles el trabajo del arquitecto. La finalidad de la arquitectura me parece que está destinada a restablecer el equilibrio entre las dos naturalezas en las que vive el hombre, aquella en la que «descansa» y aquella donde "trabaja» y "construye». Finlandia, Suecia o Dinamarca, en la década de los sesenta y en el panorama de la arquitectura europea que renacía después de la guerra, ofrecían en sus versiones orgánicas y en los trabajos del empirismo nórdico unas respuestas formales y espaciales que yo entendía que eran muy adecuadas a nuestro medio, y que sobre todo planteaban una sintonía con la gente más joven que intentaba -intentábamos afianzar la «modernidad» como negación de un pasado obsoleto.

En mi caso particular, el conocimiento de la figura de Alvar Aalto me llevó a descubrir todo el elenco del Romanticismo y Neoclasicismo nórdicos. La poética de la construcción de lugares que pude descubrir en arquitectos como G. Asplund, el sentido de la lógica del proyecto y la belleza de los materiales cuando se manifiestan en su propia naturaleza con la que A. Aalto ilustraba sus obras, me dejaron vacunado para no caer en tentaciones posteriores, tan socorridas y de tanto éxito en los «estetas reciclados» de los ochenta.

G. R. C. Para terminar este interrogatorio, y recordando que tu trabajo y el de varios de los arquitectos cuya obra se recoge en esta exposición fue definido como orgánico por los críticos, me gustaría que dijeras quiénes formabais parte de tal grupo, qué sentido le dabais entonces a ese nombre y si erais 
conscientes de tener un estilo común o reconocible con influencias mutuas.

A. F. A. Tantos interrogantes y con el requisito de apoyarlos con nombres propios me resultan difíciles porque con los años todo se inunda de niebla, afortunadamente.

El término orgánico aplicado a la arquitectura supongo que lo redactan los críticos como una metáfora analógica. Te puedo decir que no tuvo tanta fortuna como «posmoderno», tal vez porque la ironía en arquitectura se asume mejor que la sinceridad.

Por lo que respecta a las relaciones estilísticas, no dispongo de materiales adecuados para formular una reflexión tan precisa, pero sigo pensando que también hoy, para el arquitecto, no hay lugar fuera del «lenguaje» donde se pueda construir la descripción de un proyecto. 